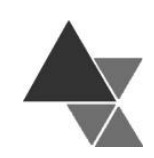

\title{
Avaliação das políticas para instalação de pontos comerciais de alimentos no interior das estações de metrô da cidade de São Paulo
}

\author{
Jessica Vaz Franco ${ }^{1}$ e Cláudia Maria Bógus ${ }^{2}$
}

Com o objetivo de descrever e compreender as políticas para instalação de pontos comerciais de alimentos no interior das estações de metrô da cidade de São Paulo e identificar se o conceito da Segurança Alimentar e Nutricional (SAN) é contemplado nesse processo, foi realizada uma análise dos documentos disponíveis e uma entrevista individual semiestruturada com informante-chave do Departamento de Negócios da Companhia do Metropolitano de São Paulo. Identificou-se que independente do tipo de comércio (vestuário, serviços, alimentos) os critérios de instalação nas estações não diferem, exceto a realização do Cadastro Municipal de Vigilância em Saúde que é a única "garantia de qualidade" dos pontos comerciais de alimentos. Não foi mencionado nos documentos o "campo" da qualidade relacionado à alimentação adequada e saudável, aos tipos de alimentos que devem ser comercializados e/ou ao tipo de ambiente que os usuários devem ser expostos. Nota-se que não é feito, pelos órgãos públicos, ações para/com esses espaços e, nem mesmo, são percebidos como um importante campo de atuação para as políticas que propõem o fortalecimento para a garantia da SAN. Considera-se, então, que a alimentação saudável deve ser incluída como um dos critérios para a instalação dos comércios de alimentos no interior das estações.

Palavras-chave: Segurança Alimentar e Nutricional, política nutricional, abastecimento de alimentos, alimentação saudável.

\section{Assessment of policies for installation of commercial food establishments inside the metro stations of the city of São Paulo}

To describe and understand the policies for installation of commercial food establishments inside the metro stations of the city of São Paulo and identify whether the concept of Food and Nutrition Security (FNS) is included in this process, an analysis of the documents available and a semi-structured interview with a key informant of the Business Department of Companhia do Metropolitano de São Paulo were conducted. It was identified that regardless of the type of trade (clothing, food services) the criteria for installation at the stations do not differ, except in relation to the Municipal Register of Health Surveillance, which is the only "quality assurance" of commercial food establishments. The "field" of quality related to adequate and healthy eating, to the types of foods that should be marketed and/or to the type of environment that users must be exposed to was not mentioned in the documents. It was noted that public agencies do not perform actions for promotion of these spaces, which are not even perceived as important for the policies that seek to ensure FNS. It is thus considered that healthy eating should be included as a criterion for the installation of commercial food establishments inside the stations.

${ }^{1}$ Mestre em Ciências pelo Programa de Pós-Graduação em Saúde Pública da Faculdade de Saúde Pública da Universidade de São Paulo. Endereço para correspondência: Av. Dr. Arnaldo no 715, Cerqueira César, São Paulo, SP, CEP: 01246-904. E-mail: jessicavazfranco@usp.br

2Professora Associada pelo Departamento de Política, Gestão e Saúde da Faculdade de Saúde Pública da Universidade de São Paulo.E-mail: claudiab@usp.br 
Keywords: Food and Nutrition Security, nutrition policy, food supply, healthy eating.

\section{INTRODUÇÃO}

Cada vez é mais frequente a realização de refeições fora de casa ${ }^{[1,2]}$ e, segundo a Pesquisa de Orçamentos Familiares 2008-2009, os grupos de alimentos com maior percentual de consumo nessas ocasiões são: bebidas alcoólicas, salgadinhos fritos e assados, pizza, refrigerantes e sanduíches ${ }^{[3]}$, ou seja, os não saudáveis/ultraprocessados.

Um relatório da Organização Pan-Americana da Saúde, de 2015, apontou que a comercialização de alimentos ultraprocessados e os níveis de obesidade no mundo têm crescido nos últimos anos ${ }^{[4]}$. Em 2010, o excesso de peso e a obesidade causaram, globalmente, 3,4 milhões de mortes, 3,9\% dos anos de vida potencialmente perdidos e $3,8 \%$ dos anos de vida perdidos ajustados por incapacidade[5].

Dentre os estudos com a temática Ambiente Alimentar, surgiu o interesse em compreender o impacto do ambiente no acesso e consumo de alimentos, não só no entorno das residências dos indivíduos, mas também nos trajetos realizados rotineiramente[6,7]. No Brasil, um estudo realizado na cidade de São Paulo concluiu que há associação entre a densidade de restaurantes, bares e lanchonetes e as áreas onde o fluxo de indivíduos é maior, como terminais de ônibus, estações de trem e metrô[ $[8]$.

A relação entre a disponibilidade de transporte público e o acesso a alimentos tem sido pouco relatada. Na Austrália, um estudo que avaliou a comercialização de alimentos em plataformas de trens por meio de vendingmachines, relatou a falta de disponibilidade de alimentos saudáveis: foram encontrados apenas 8 itens alimentares considerados como escolhas saudáveis dentre um total de 3.048 itens; o que pode ter impacto significativo nas escolhas alimentares dos passageiros ${ }^{[9]}$.

A escolha de alimentos para o consumo é influenciada por vários fatores, incluindo sabor, preço, conveniência, conhecimento e disponibilidade ${ }^{[10]}$. É importante compreender como esses fatores afetam a seleção de alimentos para traçar estratégias visando a melhoria na saúde dos cidadãos.

A promoção de um consumo alimentar mais saudável e do acesso equitativo aos alimentos envolve a construção de mecanismos de articulação entre diferentes setores e suas ações (agricultura, saúde, educação, meio ambiente, planejamento, entre outros $)^{[11]}$ que devem ser levados em consideração para a implementação de políticas públicas neste sentido.

$\mathrm{O}$ direito de acesso à alimentação adequada foi incluído entre os direitos sociais no artigo $6 \underline{o}$ da Constituição Brasileira em 2010, sendo considerado um direito humano básico. Essa inclusão foi resultado do trabalho entre: sociedade civil, organizações e movimentos sociais, órgãos públicos e privados, artistas e cidadãos de todo o país que se mobilizaram pela Campanha “Alimentação - Direito de Todos"[12].

Considera-se que para a plena realização do Direito Humano à Alimentação Adequada (DHAA) no país e, consequentemente, para a garantia da Segurança Alimentar e Nutricional (SAN) pela população brasileira é necessário, de acordo com a Lei no 11.346 de 15 de setembro de 2006[13]:

$$
\begin{aligned}
& {[\ldots . .] \text { o acesso regular e permanente a }} \\
& \text { alimentos de qualidade, em quantidade } \\
& \text { suficiente, sem comprometer o acesso } \\
& \text { a outras necessidades essenciais, tendo } \\
& \text { como base práticas alimentares } \\
& \text { promotoras da saúde que respeitem a } \\
& \text { diversidade cultural e que sejam } \\
& \text { ambiental, cultural, econômica e } \\
& \text { socialmente sustentáveis. }
\end{aligned}
$$

Esse conceito tem vinculação com o da soberania alimentar segundo o qual cada país tem o direito de definir as suas próprias políticas e estratégias sustentáveis de produção, distribuição e consumo de alimentos, de acordo com a sua necessidade, na perspectiva da promoção do DHAA[14]. Mas, é importante mencionar que o acréscimo do adjetivo "nutricional" à tradicional formulação "segurança alimentar", desde a década de 1990, é específico ao caso brasileiro, interligando os dois principais enfoques 
que estiveram na base da noção de SAN: o socioeconômico e o de saúde ${ }^{[14]}$.

Assim, a SAN se transforma em um dos eixos ordenadores das estratégias de desenvolvimento de um país: propondo formas mais equitativas $\mathrm{e}$ sustentáveis de produzir e comercializar os alimentos, questionando o padrão de consumo alimentar e requalificando as ações dirigidas, especialmente, para os grupos sociais mais vulneráveis. As ações e políticas públicas de SAN, então, possuem o grande desafio de associar o dinamismo econômico, a produção de equidade social e a melhoria sustentável da qualidade de vida ${ }^{[14]}$.

Na cidade de São Paulo é crescente o fluxo de indivíduos nos equipamentos de transporte públicos como estações e terminais de ônibus, trem e metrô e, nesses locais, há uma grande variedade de comércios de alimentos - como quiosques, lanchonetes, lojas e vendingmachines - que priorizam a venda de alimentos de maior praticidade que não demandam higienização ou necessidades de preparação em situações que requerem brevidade ao se alimentar, mas em contrapartida, podem causar impactos negativos à saúde decorrente do seu consumo frequente.

Considerando esse cenário, o presente estudo teve por objetivo descrever e compreender as políticas, as normas e/ou a regulamentação para instalação de pontos comerciais de alimentos no interior das estações de metrô da cidade de São Paulo e identificar se é considerado o conceito da SAN.

\section{MÉTODOS}

\section{Local de estudo}

A comercialização de alimentos nas dependências do Metrô de São Paulo compreende o segmento "Comércio" que, por sua vez, engloba outros tipos de produtos no ramo varejista e, somando-se com os segmentos "Inovação", "Negócios Imobiliários" e "Publicidade", representa a fonte de receita não-tarifária ou receita "acessória" da Companhia [15]. As receitas provenientes de fontes não ligadas à tarifa do serviço de transporte, como estes segmentos, existem, de acordo com a Companhia, para que o Metrô de São Paulo equilibre suas contas e realize a manutenção da prestação de serviços aos usuários, ou seja, representa um reforço de caixa que diminui a dependência de repasses do governo estadual[16]. No exercício de 2017, as receitas acessórias acumularam $\mathrm{R} \$ 248,3$ milhões, o que representou $9 \%$ da Receita Operacional Bruta desse ano[17].

Nessas dependências geralmente são encontradas as seguintes categorias de comércios: lanchonete, cafeteria, bomboniere (lojas ou quiosques que comercializam somente alimentos não saudáveis, como biscoitos, salgadinhos, refrigerantes, etc.) e vendingmachine (máquina para autosserviço que comercializa alimentos e bebidas).

Dessa forma, a fim de compreender as políticas, as normas e a regulamentação para instalação de pontos comerciais de alimentos no interior de diferentes estações administradas exclusivamente pelo Governo do Estado, este estudo foi realizado em 19 estações de cinco linhas do Metrô: 1-Azul, 2-Verde, 3Vermelha, 5-Lilás, 15-Prata. A Linha 4-Amarela não foi incluída no estudo devido à recusa, por parte da ViaQuatro, de realização da pesquisa em suas dependências. Foram estudadas as estações terminais de cada linha e as que fazem interligação com outras linhas do metrô ou do trem da Companhia Paulista de Trens Metropolitanos - CPTM.

A Tabela 1 apresenta as estações estudadas e os tipos de pontos comerciais de alimentos presentes nessas. 
Tabela 1. Número e proporção (\%) dos tipos de pontos comerciais de alimentos presentes nas estações de metrô da cidade de São Paulo. São Paulo, 2017

\begin{tabular}{|c|c|c|c|c|c|}
\hline \multirow{3}{*}{ Estação } & \multicolumn{5}{|c|}{ Tipo de ponto comercial } \\
\hline & Bomboniere & Vendingmachine & Lanchonete & Cafeteria & Total \\
\hline & n $(\%)$ & n $(\%)$ & n $(\%)$ & n $(\%)$ & n $(\%)$ \\
\hline Brás & $9(56,3)$ & $1(6,3)$ & $5(31,3)$ & $1(6,3)$ & $16(100,0)$ \\
\hline Sé & $5(35,7)$ & $6(42,9)$ & $3(21,43)$ & $0(00,0)$ & $14(100,0)$ \\
\hline Luz & $1(16,7)$ & $3(50,0)$ & $1(16,7)$ & $1(16,7)$ & $6(100,0)$ \\
\hline Ana Rosa & $2(40,0)$ & $3(60,0)$ & $0(0,0)$ & $0(0,0)$ & $5(100,0)$ \\
\hline Barra Funda & $4(100,0)$ & $0(00,0)$ & $0(0,0)$ & $0(0,0)$ & $4(100,0)$ \\
\hline Consolação & $1(25,0)$ & $3(75,0)$ & $0(0,0)$ & $0(0,0)$ & $4(100,0)$ \\
\hline República & $2(50,0)$ & $1(25,0)$ & $0(0,0)$ & $1(25,0)$ & $4(100,0)$ \\
\hline Tatuapé & $0(0,0)$ & $2(66,7)$ & $1(33,3)$ & $0(0,0)$ & $3(100,0)$ \\
\hline Itaquera & $2(100,0)$ & $0(0,0)$ & $0(0,0)$ & $0(0,0)$ & $2(100,0)$ \\
\hline Jabaquara & $2(100,0)$ & $0(0,0)$ & $0(0,0)$ & $0(0,0)$ & $2(100,0)$ \\
\hline Paraíso & $2(100,0)$ & $0(0,0)$ & $0(0,0)$ & $0(0,0)$ & $2(100,0)$ \\
\hline Tamanduateí & $1(50,0)$ & $1(50,0)$ & $0(0,0)$ & $0(0,0)$ & $2(100,0)$ \\
\hline Tucuruvi & $1(100,0)$ & $0(0,0)$ & $0(0,0)$ & $0(0,0)$ & $1(100,0)$ \\
\hline Vila Madalena & $0(0,0)$ & $1(100,0)$ & $0(0,0)$ & $0(0,0)$ & $1(100,0)$ \\
\hline Adolfo Pinheiro & $0(0,0)$ & $0(0,0)$ & $0(0,0)$ & $0(0,0)$ & $0(0,0)$ \\
\hline Capão Redondo & $0(0,0)$ & $0(0,0)$ & $0(0,0)$ & $0(0,0)$ & $0(0,0)$ \\
\hline Oratório & $0(0,0)$ & $0(0,0)$ & $0(0,0)$ & $0(0,0)$ & $0(0,0)$ \\
\hline Santo Amaro & $0(0,0)$ & $0(0,0)$ & $0(0,0)$ & $0(0,0)$ & $0(0,0)$ \\
\hline Vila Prudente & $0(0,0)$ & $0(0,0)$ & $0(0,0)$ & $0(0,0)$ & $0(0,0)$ \\
\hline Total & $32(48,5)$ & $21(31,8)$ & $10(15,1)$ & $3(4,5)$ & $66(100,0)$ \\
\hline
\end{tabular}

\section{Coleta de dados}

A coleta de dados ocorreu no primeiro semestre de 2017. Foi realizada uma busca de documentos - no website e em contato com a Companhia do Metrô - disponíveis com auxílio de um roteiro e, posteriormente, foram estudados por meio da análise documental. A utilização de documentos como material primordial nessa etapa do estudo permitiu extrair deles toda a análise, organizando-os e interpretando-os segundo os objetivos da investigação proposta ${ }^{[18]}$.

Além disso, foi realizada uma entrevista individual semiestruturada com informante-chave do Departamento de Negócios da Companhia, por ser o responsável pelas negociações com os comerciantes de todas as linhas e pelo Departamento tratarda formulação e do seguimento das políticas.

Essa entrevista composta por nove questões (Tabela 2) ocorreu no escritório da Companhia, teve a duração de 35 minutos e partiu de questionamentos básicos, apoiados em teorias e hipóteses de interesses à pesquisa ${ }^{[19]}$ : conhecer mais a fundo o que já havia sido estudado pelos documentos. Foi única, por entenderse não haver a necessidade de conversar com outros membros da equipe, já que todas as questões foram atendidas e não era de interesse do estudo compreender as percepções dos funcionários do Metrô frente às políticas e sim compreender tais políticas e seus embasamentos. 
O entrevistado foi esclarecido quanto ao objetivo geral do estudo e forneceu o consentimento livre e esclarecido para sua participação.

Tabela 2. Roteiro utilizado na entrevista com informantechave do Departamento de Negócios da Companhia do Metrô de São Paulo. São Paulo, 2017

\section{Questões do roteiro de entrevista}

1. Existem critérios, que as estações devem atender, para a implantação de estabelecimentos comerciais? Quais são eles?

2. Quando atendido os critérios, o que determina qual o tipo de estabelecimento será instalado em determinado local das estações? (vestuários, calçados, acessórios, alimentos). Deve existir alguma proporção entre os tipos de estabelecimentos? Ou só depende do interesse do comerciante?

3. Em relação aos valores de locação, como se dá a distribuição entre os diferentes tipos de estabelecimentos instalados nas estações? (vestuários, calçados, acessórios, alimentos)

4. Há diferenças de tempo de contrato dependendo do tipo/tamanho do estabelecimento?

5. No que diz respeito aos estabelecimentos que comercializam alimentos, quando começou a ser permitida a implantação destes nas estações? Como este processo se deu?

6. Quando e como começou a ser permitida a implantação de vendingmachines nas estações?

7. Quais os critérios existentes em relação aos tipos de alimentos e bebidas que estes estabelecimentos (e vendingmachines) devem comercializar?

8. Há procura/interesse, por parte dos comerciantes, para instalação de estabelecimentos com alternativas de alimentos saudáveis/naturais? De que forma esta comunicação é feita? Atende aos critérios existentes?

9. $\mathrm{O}$ (a) senhor(a) gostaria de acrescentar mais alguma coisa?

\section{Análise dos resultados}

A análise documental é importante para identificar informações factuais, a partir de questões ou hipóteses de interesse, nos documentos. Uma vez que esses constituem uma poderosa fonte de onde podem ser retiradas evidências que fundamentem afirmações e declarações do pesquisador ${ }^{[18,20]}$. Esse tipo de análise recorre a materiais que ainda não receberam tratamento analítico, ou seja, as fontes primárias: "o trabalho do pesquisador(a) requer uma análise mais cuidadosa, visto que os documentos não passaram antes por nenhum tratamento científico" [21]. $\mathrm{O}$ que permite apresentar os documentos por meio das suas referências seguidas de um resumo dos seus conteúdos e da indexação dos mesmos.

Inicia-se pela avaliação preliminar de cada documento, realizando o exame e a crítica do mesmo, sob o olhar de elementos de análise que podem variar conforme as necessidades do pesquisador. Após a análise de cada documento, segue-se a análise documental propriamente dita, que consiste no "[...]momento de reunir todas as partes - como elementos da problemática ou do quadro teórico, contexto, interesses, confiabilidade, natureza do texto, conceitos-chave"[22]. Porém, o que caracteriza a análise documental em si, é a realização dessa baseada na interpretação coerente, tendo em vista a temática proposta e a pergunta de pesquisa[23].

Dessa forma, para uma melhor leitura, organização e análise dos dados, o roteiro utilizado, foi organizado em três itens principais: 1. Disponibilidade e acesso público aos documentos (objetivo 1: apresentar o caminho e a forma de consecução desses documentos); 2. Leitura livre dos documentos (objetivo 2: caracterizar o tempo de existência do documento, as atualizações existentes e a abrangência de sua utilização de acordo com as linhas e/ou estações, se houver); 3. Identificação de critérios para instalação de pontos comerciais (objetivo 3: conhecer os critérios para instalação de pontos comerciais, como: valores, definição de tamanho e localização, menção de fiscalização e renovação, tanto dos de forma geral - vestuários, calçados, acessórios, serviços - quanto dos de alimentos - estabelecimentos e vendingmachines - para esses últimos, identificar, principalmente, os aspectos relacionados à SAN).

Embora aqui esteja sendo tratada a análise qualitativa, não se deve esquecer que, "apesar de ser mencionada como uma fase distinta denominada 'análise', durante a fase de coleta de dados a análise já poderá ocorrer" [19]. Diante disso, na medida em que os documentos eram lidos, foi realizada a organização desses em forma de textos no Word (Microsoft Word 2010) e de planilhas no Excel (Microsoft Excel 2010) devidamente identificados a fim de serem compreendidos e analisados de acordo com os itens propostos descritos no parágrafo acima.

A transcrição da entrevista realizada com informante-chave do Departamento de Negócios da Companhia e as anotações, realizadas posteriormente, totalizaram 20 páginas e serviram para complementar as informações obtidas pela análise documental, partindo do referencial teórico proposto. 
Todas as questões foram apoiadas nos itens do roteiro, destacam-se as que foram aprofundadas devido às informações não terem sido encontradas nos documentos: Q2.[...]Deve existir alguma proporção entre os tipos de estabelecimentos? Ou só depende do interesse do comerciante?; Q5. No que div respeito aos estabelecimentos que comercializam alimentos, quando comecou a ser permitida a implantação desses nas estações? Como este processo se deu?; Q7. Quais os critérios existentes em relação aos tipos de alimentos e bebidas que esses estabelecimentos (e vendingmachines) devem comercializar?, e Q8. Há procura/interesse, por parte dos comerciantes, para instalação de estabelecimentos com alternativas de alimentos saudáveis/naturais? De que forma essa comunicação é feita? Atende aos critérios existentes?

Assim, durante a análise, as falas obtidas pela entrevista contribuíram tanto para ilustrar/elucidar os textos provenientes dos documentos estudados quanto para completar as lacunas presentes nesses que eram de interesse à pesquisa.

\section{RESULTADOS}

Foram encontrados os seguintes documentos utilizados pela Companhia para a implementação de pontos comerciais, entre esses os de alimentos, no interior das estações: o Regulamento para exploração de áreas de propriedade da companhia do metrô destinadas à realização de ações promocionais, comerciais e de serviços mediante credenciamento (RECEMPE) e o Concessão de uso de áreas para exploração comercial mediante remuneração e encargos de administração, implantação, operação e manutenção, nas estações de propriedade da Companhia do Metropolitano de São Paulo - Metrô (Edital de Licitação).

A principal diferença entre esses é que no RECEMPE a instalação de pontos comerciais se dá por meio de uma Carta de Autorização de Uso (CAU) com prazo total de um ano e com valor mensal já tabelado, de acordo com a classificação das estações (Tabela 3) e com os tipos de instalações (Tabela 4)entre os tipos de instalações para comércio de alimentos, as máquinas dispensadoras de produtos e serviços continham valores mais baixos em relação aos demais e os valores $/ \mathrm{m}^{2}$ mais barato correspondiam às estações pertencentes ao grupo $\mathrm{D}$ e os mais caros ao grupo Especial (Tabela 5). Já no Edital de Licitação ocorre uma disputa por Pregão Eletrônico em que o valor mínimo é o determinado pelo RECEMPE e o comerciante com o melhor lance ganha a licitação de operação com um prazo de cinco anos.

Tabela 3. Classificação das estações segundo grupos. São Paulo, 2017

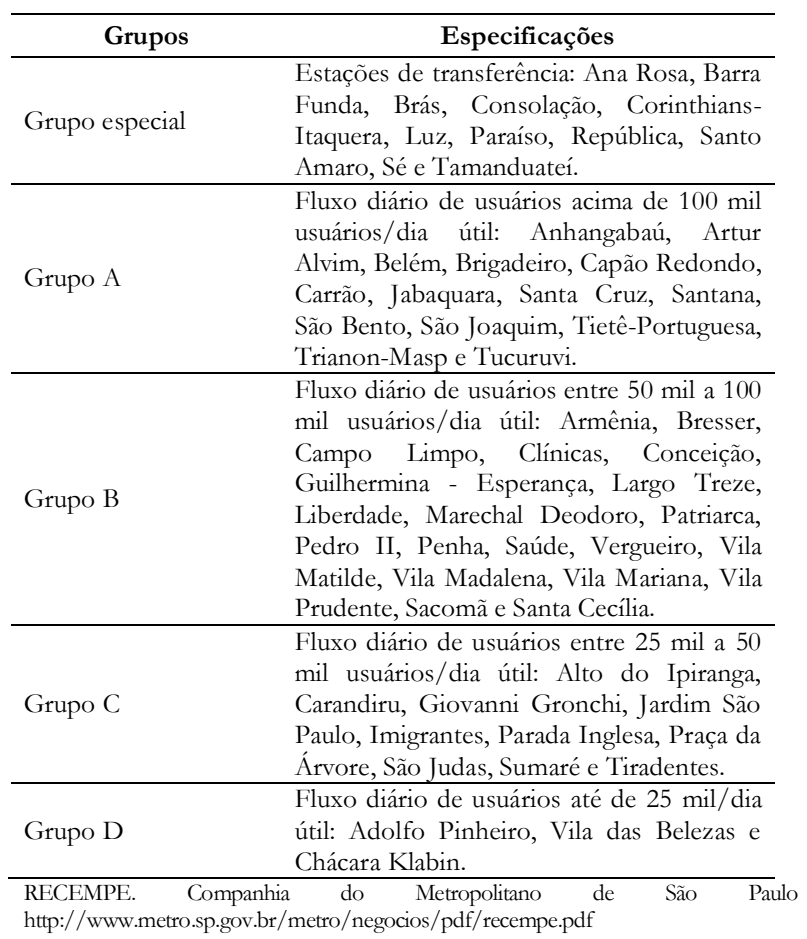


Tabela 4. Opções de tipo de instalações no interior das estações do Metrô de São Paulo. São Paulo, 2017

\begin{tabular}{ll}
\hline Tipo de instalações & \multicolumn{1}{c}{ Definições } \\
\hline Aparelhos Bluetooth & Aparelhos eletrônicos com tecnologia bluetooth. \\
\hline Equipamentos de tecnologia sem & $\begin{array}{l}\text { Fornecimento gratuito aos usuários do Metrô de serviço de acesso à internet de alta velocidade e } \\
\text { em quantidade de conexões simultâneas proporcional ao fluxo de pessoas do local selecionado, } \\
\text { com instalação da infraestrutura necessária mediante aprovação prévia de projeto técnico da } \\
\text { Credenciada pela Cia do Metrô, com autorização para exploração comercial do conteúdo virtual, } \\
\text { conforme legislação vigente. }\end{array}$
\end{tabular}

Exploração temporária e precária de terrenos da Companhia do Metrô para utilização como

Estacionamento estacionamento.

Estande comercial* Destinado ao comércio de produtos embalados industrialmente (à exceção de café, refrigerantes e

Estande promocional* sorvetes no caso de alimentos), pertencentes a uma única marca, com possibilidade de venda direta.

Estande promocional com vendas Destinado à promoção (divulgação) de produto/serviço de uma única marca.

Estande promocional com vendas $\begin{aligned} & \text { Destinado a venda direta ou } \\ & \text { comercialização de alimentos }\end{aligned}$

Eventos

Atividades específicas cuja realização fica condicionada à aprovação de critérios técnicos e operacionais pelo Metrô, tais como: desfile, evento temático, show, festa, lançamento, entre outros, em trens, estações, áreas remanescentes e outros terrenos de propriedade da Companhia do Metrô.

Feiras*

Conjunto de estandes com estrutura autoportante de montagem e desmontagem rápida, composta de vidros na fachada principal e divisórias com bom padrão de acabamento.

\begin{tabular}{|c|c|}
\hline Lojas* & $\begin{array}{l}\text { Em alvenaria, destinadas ao comércio ou prestação de serviços em estações, áreas remanescentes e } \\
\text { outros terrenos de propriedade da Companhia do Metrô. }\end{array}$ \\
\hline Máquinas de Autoatendimento & Equipamentos mecanizados auto operáveis, operadoras de serviços sem a utilização de numerário. \\
\hline $\begin{array}{l}\text { Máquinas dispensadoras de } \\
\text { produtos e serviços* }\end{array}$ & Equipamentos mecanizados auto operáveis, dispensadores de produtos e/ou serviços. \\
\hline Mockup* & Elemento tridimensional utilizado para a divulgação e promoção de produtos. \\
\hline Outros Formatos & Propostas de produtos não previstos e que podem gerar receita por meio de outros formatos. \\
\hline Performance & Atividade promocional realizada por promotores (as) nas estações e/ou trens. \\
\hline $\begin{array}{l}\text { Pontos para Parada de ônibus em } \\
\text { baias de Terminais Urbanos }\end{array}$ & $\begin{array}{l}\text { Área para embarque e desembarque de passageiros de empresas de transporte coletivo privado, sem } \\
\text { cobrança de tarifas diárias. }\end{array}$ \\
\hline Quiosques comerciais* & $\begin{array}{l}\text { Estruturas autoportantes de fácil montagem e desmontagem, resistentes às condições climáticas } \\
\text { localizados nos Terminais Urbanos de Ônibus, áreas externas às estações. }\end{array}$ \\
\hline Sampling* & Distribuição de amostras grátis de produtos embalados industrialmente. \\
\hline Totens de mídia* & $\begin{array}{l}\text { Estrutura autoportante modular de montagem e desmontagem rápida destinada à veiculação de } \\
\text { uma única campanha publicitária de um único anunciante. }\end{array}$ \\
\hline Totens Sinalizadores & Estrutura autoportante, utilizada para a divulgação de localização ou acesso a eventos. \\
\hline Vitrines & Aquelas com estrutura para exposição de produtos. \\
\hline
\end{tabular}


Tabela 5. Tabela de remuneração para instalação de produtos comerciais destinados a alimentos nas dependências das estações. São Paulo, 2017

\begin{tabular}{|c|c|c|c|}
\hline Produto & Preço (R\$) & Condições & $\begin{array}{l}\text { Valor por } \\
\mathrm{m}^{2} / \text { unidade } \\
\text { adicional }\end{array}$ \\
\hline \multirow{5}{*}{ Estande Promocional } & $5.565,30$ & Valor mínimo $4 \mathrm{~m}^{2} /$ estande - Grupo Especial & $1.391,33$ \\
\hline & $5.064,00$ & Valor mínimo $4 \mathrm{~m}^{2} /$ estande - Grupo A & $1.266,00$ \\
\hline & $4.357,20$ & Valor mínimo $4 \mathrm{~m}^{2} /$ estande - Grupo B & $1.089,30$ \\
\hline & $3.269,10$ & Valor mínimo $4 \mathrm{~m}^{2} /$ estande - GrupoC & 817,28 \\
\hline & $2.943,00$ & Valor mínimo $4 \mathrm{~m}^{2} /$ estande - GrupoD & 735,75 \\
\hline \multirow{5}{*}{ Estande Comercial } & $13.436,70$ & Valor mínimo $20 \mathrm{~m}^{2} /$ estande - GrupoEspecial & 671,84 \\
\hline & $12.235,20$ & Valor mínimo $20 \mathrm{~m}^{2} /$ estande - GrupoA & 611,76 \\
\hline & $10.777,50$ & Valor mínimo $20 \mathrm{~m}^{2} /$ estande - GrupoB & 538,88 \\
\hline & $9.524,70$ & Valor mínimo $20 \mathrm{~m}^{2} /$ estande - GrupoC & 476,24 \\
\hline & $8.700,00$ & Valor mínimo $20 \mathrm{~m}^{2} /$ estande - GrupoD & 435,00 \\
\hline Feiras & $18.736,20$ & $60 \mathrm{~m}^{2} /$ estação & 312,27 \\
\hline \multirow{5}{*}{ Lojas } & 521,40 & Valor/m² - GrupoEspecial & 521,40 \\
\hline & 459,90 & Valor $/ \mathrm{m}^{2}-$ GrupoA & 459,90 \\
\hline & 401,10 & Valor $/ \mathrm{m}^{2}-$ GrupoB & 401,10 \\
\hline & 342,00 & Valor $/ \mathrm{m}^{2}-$ GrupoC & 342,00 \\
\hline & 303,30 & Valor $/ \mathrm{m}^{2}-$ GrupoD & 303,30 \\
\hline $\begin{array}{l}\text { Máquina Dispensora de Produtos e } \\
\text { Serviços }\end{array}$ & $1.550,00$ & Valor/Máquina & $1.550,00$ \\
\hline MockUp & $5.395,20$ & $4 \mathrm{~m}^{2}$ & $1.348,80$ \\
\hline \multirow{4}{*}{ Quiosques } & $5.129,40$ & $\begin{array}{l}\text { Mínimo de } 4 \mathrm{~m}^{2} \text { /quiosque - Estações: COM, } \\
\text { PPQ, SAN, ANR, ART, PEN, CAR, TAT, BEL } \\
\text { (norte), DEO* }\end{array}$ & $1.282,35$ \\
\hline & $4.607,70$ & $\begin{array}{c}\text { Mínimo de } 4 \mathrm{~m}^{2} / \text { quiosque - Estações: JAB, } \\
\text { VTD, BEL (sul)* }\end{array}$ & $1.151,93$ \\
\hline & $4.135,80$ & $\begin{array}{l}\text { Mínimo de } 4 \mathrm{~m}^{2} / \text { quiosque }- \text { Estações: VMD, } \\
\text { BFU* }\end{array}$ & $1.033,95$ \\
\hline & $3.039,00$ & $\begin{array}{c}\text { Mínimo de } 4 \mathrm{~m}^{2} / \text { quiosque - Estações: PIG, } \\
\text { PCA* }\end{array}$ & 759,75 \\
\hline Sampling Distribuição de Amostras & 698,10 & Por promotor(a)/dia. Horário: $10 \mathrm{~h} 00$ às $16 \mathrm{~h} 00$ & 698,10 \\
\hline Totem de Mídia & $6.204,60$ & Valor/Totem & $6.204,60$ \\
\hline
\end{tabular}

Independente do tipo de produto/comércio (vestuário, serviços, alimentos) os critérios de instalação nas estações (Tabela 6) não diferem. 
Tabela 6.Critérios para instalação de pontos comerciais nas estações segundo os documentos RECEMPE e Edital e Licitação. São Paulo, 2017

1) Após o Aviso de Credenciamento, pessoas jurídicas interessadas em instalar um ponto comercial, podem solicitar credenciamento junto à Companhia. 2) Essas devem encaminhar alguns documentos que serão analisados a fim de ser emitido o Certificado de Credenciamento, tais como: a prova de inscrição do Cadastro Nacional de Pessoa Jurídica (CNPJ), prova de regularidade fiscal perante a Seguridade Social e Fazenda Nacional, prova de inexistência de débitos inadimplidos perante a Justiça do Trabalho, entre outros. 3) Feito o credenciamento junto à Companhia, é necessário realizar uma Solicitação de Uso com as seguintes informações: RECEMPE número do certificado de credenciamento, período pretendido de utilização, indicação do produto pretendido e dos locais desejados, nome e cargo do representante legal que assinará a CAU, entre outros. 4) Após a confirmação, pela Companhia, de disponibilidade de local, é necessário o encaminhamento, a saber: projeto em conformidade com as exigências técnicas feitas pela Companhia do Metrô, registro de responsabilidade técnica, cópia do contrato firmado com o cliente (para os casos do Credenciado ser franqueado), amostra do leiaute, apresentação do mix de produtos a serem comercializados, entre outros. 5) Após essas etapas e para a utilização das áreas disponíveis, a Companhia do Metrô emitirá a CAU. E a Credenciada passa ser chamada de Autorizada.

1) Após a divulgação do Edital de Licitação, poderão participar do processo de licitação na modalidade Pregão (do tipo maior oferta): pessoas jurídicas interessadas que tiverem registro no Cadastramento de Fornecedores através da Bolsa Eletrônica de Compras do Governo do Estado de São Paulo, em atividade compatível com o objeto da licitação, que sejam isentos a qualquer fator que impeça a sua participação e/ou contratação. 2) As propostas deverão ser enviadas por meio eletrônico disponível com outros documentos, tais como: carta comercial, prova de inscrição no CNPJ, certificado de regularidade perante o FGTS, prova de inexistência de débito perante a Justiça do Trabalho, comprovação de boa situação financeira, experiência para desenvolver negócio pertinente com a proposta apresentada na licitação, entre outros. 3) Quando iniciada a etapa de lances, serão convidadas a participar todas as pessoas jurídicas com propostas aprovadas, que deverá lançar no sistema do Pregão Eletrônico o valor para proposta comercial. 4) Divulgado o resultado de licitação, haverá um prazo para manifestações sobre a intenção de interpor recurso. 5) Decididos os recursos e constatada a regularidade dos atos praticados, a autoridade competente adjudicará o objeto da licitação à vencedora e homologará o procedimento. 6) Após o recebimento dessa comunicação, deverá ser apresentado: o mix dos produtos a serem comercializados, no regime de Franquia ou de "marca licenciada", deve-se apresentar o instrumento que comprove o vínculo entre partes, devolver o Contrato assinado pelos representantes legais em duas vias, entregar a Garantia de Execução Contratual no valor de 5\% do valor de cada Oferta de Compra adjudicada, referente ao período de 12 meses, com prazo de validade que abrange todo o período de vigência do contrato, entre outros. 7) Assim, a vencedora, passa a ser habilitada sob condição contratual.

A Companhia apontou a existência de erros nos valores dos pontos comerciais:

Pelo RECEMPE é tabelado, igual pra todo mundo, e aí não tem distinção de produto. É o $\mathrm{m}^{2}$, o valor do $\mathrm{m}^{2}$, a gente entende que tem algumas distorções aí, ainda não tivemos tempo para revisar isso. Porque alimentação, por exemplo, deveria ser um valor um pouco mais alto e serviços, que é uma coisa que estamos tentando trazer pra dentro do Metrô, deveria ser um pouco mais baixo. Isso para o futuro a gente vai conseguir (Informante-chave do Departamento de Negócios da Companhia).
Pareceu ser recente a implementação de pontos comerciais no Metrô por meio de Licitação e já se tornou a forma preferencial pela Companhia e pelos comerciantes, segundo o entrevistado, pois há um longo prazo de contrato e renovação:

Por CAU que é o RECEMPE deve ser no máximo por um ano. Isso torna um pouco ingrato né, porque a pessoa investe, gasta um dinheiro e tem que tentar o resultado em um ano e nem sempre é possível [...]Ele é muito bom, mas ele tem que ser utilizado para o que ele foi criado. Então são experiências, são empreendimentos de curto prazo, de ações promocionais [...]Até o ano passado [2016] 75\% era RECEMPE e uma das primeiras coisas que me foi encomendado quando vim 
trabalhar aqui [há dois anos] falaram assim 'olha, tem que licitar porque a licitação é melhor' [...]Já licitamos agora em 2017, 106 pontos comerciais. E todos de modo geral preferem, porque agora eles têm cinco anos. Então vão poder trabalhar, sabe quantos empregados, o treinamento, o tipo de produto, vai investir na qualidade $\mathrm{da}$ loja (Informante-chave do Departamento de Negócios da Companhia).

Mas há alguns tipos de comércios que não se adaptam bem por meio de licitação, como as máquinas dispensadoras de produtos (ou vendingmachines):

Para vendingmachine a exigência é a mesma, mas foi um produto que não deu certo por licitação. Hoje se alguém quiser colocar uma máquina, ela vai se credenciar no Metrô, mandar uma carta dizendo qual é a estação que tem interesse e a gente autoriza ou não, aí por CAU mesmo. Porque assim, quando licito eu digo 'olha, você vai operar na estação Jardim São Paulo a sua máquina' aí ele 'ah, que ótimo! eu quero!' No mês seguinte ele pede pra mudar dessa estação porque não teve movimento suficiente. Como eu licitei, eu não posso autorizar. Então no caso de máquina, a flexibilidade é importante. Praquando a pessoa for renovar CAU, renovar num outro ponto, fazer alguns testes (Informantechave do Departamento de Negócios da Companhia).

Para alimentação, além dos procedimentos para a instalação de pontos comerciais de modo geral, também é necessário à apresentação do Cadastro Municipal de Vigilância em Saúde (CMVS) e após a autorização, cumprir rigorosamente com as legislações sanitárias. É estabelecido nos documentos também que a Companhia poderá solicitar que as autoridades federais, estaduais e municipais, ligadas aos órgãos de saúde pública efetuem a fiscalização da área, das instalações e dos equipamentos utilizados.

E o entrevistado completa: "Pra tentar garantir um pouco a qualidade né?! Independente de onde seja, se for quiosque em terminal ou lojas dentro das estações, todos têm que ter o cadastro [...] Quem não tiver a gente não permite que funcione"
(Informante-chave do Departamento de Negócios da Companhia).

Já há algum tempo são comercializados alimentos nas estações:

No mínimo uns 10 anos que já existem. Já foram feitas várias tentativas também. Teve, por exemplo, no passado, teve um projeto chamado "Estação Economia" e as pessoas vendiam hortifrutigranjeiros, vendia ovo assim... eram alguns espaços juntos às estações e as pessoas comercializavam isso. Depois foi derivando... até que passou a autorizar a comercialização de alimentos preparados dentro das estações. $\mathrm{E}$ isso já faz sete... oito anos... que já existe comercio de alimentação do Metrô. Vem sendo aprimorado, em 2016 a nossa grande meta foi exigir que todos os que vendem alimentos tivessem $\mathrm{O}$ CMVS com treinamento (Informantechave do Departamento de Negócios da Companhia).

A Companhia pareceu reconhecer as dificuldades de se ter pontos comerciais em uma rede de transporte público:

O comércio hoje ele já tá absorvido pela estação, mas ele é um elemento estranho né?! É um sistema de transporte, foi feito pra transporte, não foi feito pra comércio. Hoje é até uma discussão grande que a gente tem interna na Companhia, pra que nas próximas estações seja pensado o espaço comercial como elemento dentro de uma estação. Pra que a gente não tenha que fazer remendos $\mathrm{e}$ adaptações (Informante-chave do Departamento de Negócios da Companhia).

Os documentos informam que ocorrem divulgações da existência de espaços disponíveis por meio de publicação, realizada pela Companhia do Metrô, com detalhes das estratégias comerciais pretendidas. Sobre os espaços, o informante-chave do Departamento de Negócios da Companhia esclareceu como ocorrem as definições: 
A gente analisa algumas métricas e tem algumas diretrizes. Por exemplo, as estações têm uma variação muito grande de linha pra linha. Então a gente tem muito espaço em algumas, pouco espaço em outras. Às vezes as que têm muito espaço, não são boas comercialmente, por conta do volume de passageiros. $\mathrm{E}$ as vezes as que tem um volume de passageiros muito grande, a gente não tem tanto espaço. Então a gente tem que considerar primeiro essas peculiaridades do sistema [...]Às vezes até a infraestrutura eu tenho que considerar também, se eu tenho estação onde eu sei que não consigo fornecer energia elétrica pra funcionar uma lanchonete [...]A segunda coisa que a gente faz é avaliar um pouco qual o perfil do comércio que já está instalado. Então, se eu tenho, por exemplo, cinco espaços e três eu já tenho venda de alimentação, os outros dois quando eu colocar à disposição do mercado, eu vou tentar que não seja alimentação pra manter certo equilibrio (Informante-chave do Departamento de Negócios da Companhia).

Há estações nas quais o único ponto comercial apropriado devido ao fluxo de usuários é vendingmachine:

Tem estação que eu não consigo colocar nada, só máquina. Entrevistadora: Estações menores? É principalmente estações menores. Mas às vezes são estações que eu não tenho tanto passageiro, tanto público. E aí é assim, entre a pessoa colocar uma máquina e vai pagar $\mathrm{R} \$ 1.550,00$ por mês ou pagar um estande comercial de $4 \mathrm{~m}^{2}$ que vai pagar $\mathrm{R} \$ 6.000,00$, ele prefere colocar uma máquina. E $\mathrm{O}$ usuário gosta (Informante-chave do Departamento de Negócios da Companhia).

E ainda há aquelas em que não há a possibilidade de instalar pontos comerciais, seja devido ao espaço e/ou ao tipo de administração a qual está submetida: se eu licitar agora por quatro/cinco anos, possivelmente, a pessoa vai ficar quatro anos com outro chefe. Então era ruim pra gente, não licitamos nada por conta disso. E é uma estação que ainda não tem uma conexão com $\mathrm{O}$ Metrô. Ela conecta com o trem só. Agora que vão começar a inaugurar as estações, a hora que ela chegar na 1Azul, possivelmente ela vai ser mais movimentada do que da Zona Leste. E aí a gente entende que o comércio vai ser importante, mas não dá pra gente fazer agora... daria pra fazer por CAU, só que o que acontece, são estações que como são muito acanhadas, elas foram muito adaptadas. Então tem uma dificuldade muito grande em fornecer energia elétrica. E o Metrô tem que fornecer dependendo de onde estiver localizado. Já a Linha 15-Prata ainda não dá [pra instalar pontos comerciais]... Não tem tanto movimento, têm 15mil pessoa/dia... Não dá nem pra "fazer barulho" (Informante-chave do Departamento de Negócios da Companhia).

Os aspectos relacionados à SAN presentes no RECEMPE e no Edital de Licitação, dizem respeito apenas aos critérios da segurança dos alimentos no que tange as "questões higiênico-sanitárias" de manuseio, preparo, armazenamento entre outras que auxiliam na conservação/preservação físicas dos alimentos para o consumo através do CMVS. Não foi mencionado nos documentos o "campo" da qualidade relacionado à alimentação adequada e saudável, aos tipos de alimentos que devem ser comercializados e/ou ao tipo de ambiente que os usuários devem ser expostos.

Além disso, durante a entrevista foi possível perceber a preferência por fastfood's.

[...] $\mathrm{O}$ usuário do Metrô gosta de marca. Ele gosta de ver marcas conhecidas. E a gente queria uma marca pra mostrar que não precisa ser só o cara que vende pão de queijo e que no Metrô pode ter algumas marcas. O [estabelecimento conbecido pela venda de coxinhas a baixo custo 7 tinha procurado a gente, nós fizemos alguns testes, percorremos várias estações e eles optaram por Sé e a gente conseguiu autorização pra colocar ali em Sé. Então a gente tenta atrair, tenta variar... Já falamos com $[a$ maior rede de fastfood conbecida mundo afora],
A Linha 5-Lilás, porque a gente não tem tanto [ponto comercial:: Primeiro porque o governo vai privatizar, então 
já falamos com la rede concorrente direta desta anterior], já falamos quem você imaginar... E você pode me perguntar 'ah, mas porque fastfood? Porque o metrô tem que ser fast. Não tem jeito! [...] O povo do Metrô se demorou, eles vão embora. Vão pra outro. Se tiver fila não vai. Não pára. A pessoa desce no metrô pensando no trem, desce no trem pensando no metrô lem estações de transferencia] (Informante-chave do Departamento de Negócios da Companhia).

Sobre o interesse na existência de "marcas" em estações, o entrevistado continua:

Há dois anos, nós fizemos projetos sazonais de natal pra vender panetone. Então a gente identificava alguns locais pra autorizar o cara [marcas de panetone/comerciante] a ficar quatro meses, cinco meses... No primeiro ano teve um. No segundo ano a gente teve 14. Então assim, eles perceberam. A gente tenta estimular, tenta atrair, mas nem sempre consegue. Então a gente tá tentando por licitação agora, eu já estou com o anuário das franquias [de lanchonetes famosas] aqui, já estamos fazendo contato com elas dizendo 'olha, nós vamos abrir, por favor, quem tiver interesse participe' (Informantechave do Departamento de Negócios da Companhia).

E quando o informante-chave do Departamento de Negócios da Companhia foi questionado sobre a procura, por parte dos comerciantes e da Companhia, em instalar outras opções de comércios "não fast", ele deu exemplo de uma loja existente que também parece atrair os usuários:

Estamos implantando agora uma marca, não é bem uma marca... Que vende produtos naturais. Ela abriu a primeira loja em Brás, por CAU, no ano passado e está fazendo um ano agora. Nós fizemos licitação e eles conseguiram mais seis pontos [comerciais]. O produto deles é natural, lanche natural, wrap, aveia, castanha, e quando você vê o perfil do consumo do metrô você pensa 'será que vai dar certo isso?' Pode perguntar pra ela $[a$ dona da loja]! Quando abriu no Brás, no terceiro dia já tinha superado todas as expectativas dela (Informante-chave do Departamento de Negócios da Companhia).

Todavia, na conclusão dessa fala, a venda de alimentos saudáveis não pareceu ser vista como um bem ao usuário (no sentido de pensar em sua saúde) e sim, como mais uma opção de lucro:

Ela [dona da loja] sempre quer vender assim produtos diferenciados. Ela fala que 'não quero vender pão de queijo e esses salgados bastante encontrados por aqui [na estação], já vendi isso no passado é assim, você vende o dia inteiro e depois você vai ver o que ganhou e é muito pouco'. Então ela falou 'prefiro vender umas coisinhas um pouco mais caras, mas que eu me diferencie da concorrência'. Isso é legal, isso pra gente é perfeito. É o que a gente quer, o usuário do Metrô também fica feliz. [...]Já recebemos elogios dessa loja, pessoas mandando 'olha parabéns, uma loja muito bem montada, produtos bons'Informantechave do Departamento de Negócios da Companhia).

\section{DISCUSSÃO}

O grande fluxo de usuários nas dependências do metrô é um fator determinante para a presença de pontos comerciais de alimentos e, ainda, reflete diretamente no valor do espaço a ser utilizado pelos comerciantes e no tipo de alimentos ofertados. $\mathrm{O}$ fato de haver dois documentos para a instalação de pontos comerciais nas estações possibilita opções de escolha aos comerciantes de acordo com suas necessidades. Os mesmos podem apenas "testar" a eficácia de seus empreendimentos em curto prazo (RECEMPE) ou, caso já trabalhem com o ramo pretendente, podem têlo por longo prazo nas dependências da Companhia do Metrô (Edital de Licitação).

Apesar da venda de alimentos nos espaços das estações existir, nesse formato, ao longo de oito anos, apenas há dois anos que o CMVS passou a ser exigido a todos os comerciantes, de acordo com o entrevistado. Esse cadastro é a única "garantia de qualidade" dos pontos comerciais e dos seus alimentos descrita nos documentos estudados da Companhia. Não excluindo a sua importância no comércio de 
alimentação, mas trata-se apenas dos aspectos sanitários de produção e comercialização dos alimentos. Ou seja, é um registro obrigatório dos dados de identificação de estabelecimentos e equipamentos de interesse da saúde no órgão de vigilância em saúde do município, neste caso o Comércio Varejista de Alimentos, bem como a autorização para o início de suas atividades, conforme o Decreto Municipal no 57.486, de 1ㅇ de dezembro de 2016 [24] que regulamenta a Lei Municipal no 13.725/04 (Código Sanitário do Município de São Paulo) ${ }^{[25] .}$

É obtido através de requerimento padronizado pela Portaria CMVS - 2215/2016[26] - no qual os responsáveis pelos pontos comerciais de alimentos declaram que suas atividades, instalações, equipamentos e recursos humanos obedecem à legislação sanitária vigente, através do cumprimento das condições sanitárias e técnicas das atividades relacionadas ao controle de pragas, acondicionamento adequado de resíduos, controle de qualidade, à higiene e controle de saúde e capacitação dos funcionários, importação, exportação, extração, produção, manipulação, ao acondicionamento, transporte, armazenamento, d̀ distribuição, embalagem/reembalagem, ao fracionamento e uso de alimentos e à comercialização.

Mas, também, não se pode deixar de considerar os aspectos relacionados a SAN (que tem como base práticas alimentares promotoras da saúde), principalmente por ser um equipamento público e por existir políticas e ações brasileiras que buscam incansavelmente: respeitar, proteger, promover, prover, informar, monitorar, fiscalizar e avaliar a realização do DHAA, bem como garantir os mecanismos para sua exigibilidade[13]. Entre elas destacam-se: a Política Nacional de Alimentação e Nutrição[27], o Programa de Aquisição de Alimentos (PAA) ${ }^{[28]}$, a Política Nacional de Segurança Alimentar e Nutricional[13], o Plano Nacional de Segurança Alimentar e Nutricional[29], a Política Nacional de Agroecologia e Produção Orgânica (PNAPO) [30] e o Pacto Nacional para a Promoção da Alimentação Saudável[31]. O Brasil ainda está articulado em ações a nível internacional, como: Agenda 2030 para o desenvolvimento sustentável[32] e a Década de ação das Nações Unidas sobre nutrição (2016-2025) (ou "Década da Nutrição")[33]. Podem-se citar, também, as ações e políticas existentes na cidade de São Paulo, a saber: o 1 Plano Municipal de Segurança Alimentar e
Nutricional (PLAMSAN) ${ }^{[34]}$ e o Pacto de Milão sobre Políticas Públicas Alimentares Urbanas ${ }^{[35] .}$

Nota-se que não é feito, pelos órgãos públicos, ações para/com esses espaços e, nem mesmo, os considera como um importante campo de atuação para as políticas que propõem o fortalecimento para o alcance da SAN. Além do mais, por parte da Companhia, não foi possível identificar uma priorização na criação de ambientes saudáveis. Isso ficou claro devido preferência porfastfood -“o metrô é fast", disse o entrevistado - e a busca constante em atrair as grandes empresas neste ramo como uma justificativa para "satisfazer os usuários que gostam de marcas". Mas, ao mesmo tempo, estes usuários elogiam a loja que apresenta opções de alimentos saudáveis. A Companhia, por sua vez, só a vê como outra opção de lucro pela venda de itens mais caros.

Crítica que também se estende à atual política do Poder Executivo do Estado de São Paulo, pois no passado outras políticas, do Poder Executivo estadual, viram a possibilidade de acesso à alimentação saudável no Metrô: o programa Estação Economia, mencionado na entrevista, foi desenvolvido em 1993[36] pela Secretaria de Agricultura e Abastecimento do Estado de São Paulo e através da Coordenadoria do Desenvolvimento dos Agronegócios e tinha o intuito de criar um canal direto entre produtores e consumidores da região metropolitana de São Paulo, através do apoio ao escoamento dos produtos hortifrutigranjeiros e da viabilização da aquisição destes por parte de toda a população, sobretudo a de renda mais baixa, já que os preços dos alimentos eram abaixo dos praticados em supermercados e feiras. Para isto foram criados pontos de venda em locais com grande fluxo de pessoas, ou seja, as estações do Metrô, da CPTM e da EMTU[37].

O Programa Estação Economia chegou a comercializar de dez a doze mil toneladas/ano de produtos alimentícios básicos e de época entre eles: $\mathrm{F} \& \mathrm{H}$, frango, laticínios, ovos e mel diretamente dos produtores e sem uso de agrotóxicos ${ }^{[37]}$. Mas, há algo curioso nas publicações sobre o Programa daquele período, como a venda de outros tipos de alimentos como salsicha, linguiça, mortadela ${ }^{[37]}$ e panetones ${ }^{[38]}-$ esse último havia uma promoção de Natal "pacote natalino a um preço popular" vendido junto às "frutas de Natal". Não se sabe a procedência desses, mas 
pode ser que a derivação, dita pelo informante-chave do Departamento de Negócios da Companhia, tenha começado a despertar nesse momento.

Não há maiores informações sobre o fim do Programa, no entanto, até meados de 2006 ainda havia publicações a respeito[39], ou seja, no passado foi um dos planos de ação do governador Geraldo Alckmin (nos períodos de 6 de março de 2001 a 1 de janeiro de 2003 e 1 de janeiro de 2003 a 31 de março de 2006), que estava em exercício quando o estudo foi realizado.

Conforme citado na introdução: A implementação de políticas públicas voltadas ao acesso de alimentos saudáveis, envolve a articulação entre diferentes setores e suas ações como agricultura, saúde, educação, meio ambiente, planejamento, entre outros ${ }^{[1]}$, cabe aos governantes, por exemplo, intervir na cadeia agroalimentar para permitir que setores excluídos tenham acesso à alimentação saudável a partir de arranjos produtivos sustentáveis ambientalmente[40]. É importante, então,a recuperação do papel regulatório do Estado em relação às políticas públicas em torno do interesse e do bem público.

Os Governos Municipal e Estadual devem desempenhar a execução de políticas públicas que estimulem a produção e comercialização de alimentos saudáveis em conjunto, para uma maior efetividade. Estação Economia (em sua versão inicial com a venda apenas de hortifrutigranjeiros), por exemplo, poderia servir de modelo para as ações previstas no PLAMSAN e no Pacto de Milão, além de futuras políticas públicas associadas às de âmbito federal, como o PAA e PNAPO.

É necessário o resgate das práticas alimentares sob o ponto de vista da SAN nos equipamentos de transporte público (através da reconexão produtorconsumidor, da valorização do produtor e do alimento, da melhor qualidade dos alimentos, do respeito à sazonalidade, do estimulo à "comida de verdade" e da possibilidade da compra de alimentos orgânicos). Mas, para isso, não se pode deixar de considerar os fatores necessários para efetivação da compra dos alimentos saudáveis, sobretudo nas estações do metrô: preço e praticidade.

\section{CONCLUSÃO}

Foi possível compreender as políticas para instalação de pontos comerciais de alimentos no interior das estações de metrô da cidade de São Paulo. Apesar do comércio ser reconhecido como um elemento não convencional no transporte público em questão, poucos são os fatores que intimidam a sua instalação (infraestrutura física, fornecimento de energia e número de passageiros), as próximas estações já serão projetadas para haver um espaço adequado destinado à comercialização de alimentos, espécie de praça de alimentação, e nas que já existem, continuará sendo feita as demarcações, os croquis e os estudos para suportá-los.

A única exigência diretamente relacionada à venda de alimentos, para/com os comerciantes, é a existência do CMVS do estabelecimento - reflexo da falta de controle e valorização da importância, por parte da Companhia, do tipo de alimento que deve ser comercializado nas estações. Dessa forma, fica claro que alimentação saudável não é incluída como um dos critérios para a instalação desses pontos comerciais e que, consequentemente, o conceito de SAN sequer é considerado.

Esses dados podem despertar o interesse do poder público na formulação de intervenções, políticas públicas e regulamentações, que considerem a realização do DHAA como um objetivo central, aplicadas a esse contexto. Por se tratar de um equipamento prestador de serviços públicos e pela existência de políticas, ações e estratégias nacionais e municipais que buscam a garantia da SAN, esse deve promover ambientes saudáveis aos seus usuários: ampliando a participação pública sobre os preços, as propagandas e promoções, a qualidade e variedade dos alimentos comercializados e incentivando a produção e consumo de alimentos regionais.

As autoras agradecem o apoio do $\mathrm{CNPq}$ (processo: 34255/2016-0) e FAPESP (processo: 2016/03313-8)

\section{REFERÊNCIAS}

[1] Bezerra IN, Curioni C, Sichieri R. Association between eating out of home and body weight. Nutr. Rev. 2013;70(2):65-79. 
[2] Bandoni DH, Canella DS, Levy RB, Jaime PC. Eating out or in from home: analyzing the quality of meal according eating locations. Rev. Nutr. 2013;26(6):625-632.

[3] Instituto Brasileiro de Geografia e Estatística. Pesquisa de Orçamentos Familiares 2008-2009: análise do consumo alimentar pessoal no Brasil. Rio de Janeiro: IBGE; 2011.

[4] Pan American Health Organization. Ultra-processed food and drink products in Latin America: Trends, impact on obesity, policy implications. Washington, DC: PAHO; 2015.

[5] Ng M, Fleming T, Robinson M, Thomson B, Graetz N, Margono C, et al. Global, regional, and national prevalence of overweight and obesity in children and adults during 1980-2013: a systematic analysis for the Global Burden of Disease Study 2013. The Lancet 30. 2014;384(9945):766-781.

[6] Burgoine T, Monsivais P. Characterising food environment exposure at home, at work, and along commuting journeys using data on adults in the UK. Int. J. Behav. Nutr. Phys. Act. 2013;10:85.

[7] Moore K, Diez-Roux AV, Auchincloss A, Evenson KR, Kaufman J, Mujahid M, et al. Home and Work Neighborhood Environments in Relation to Body Mass Index: the Multi-Ethnic Study of Atherosclerosis (MESA). J. Epidemiol. Community Health. 2013;67(10):846-853.

[8] Canella DS, Duran ACFL, Tavares TF, Jaime PC. A circulação de pessoas influencia a disponibilidade de restaurantes, bares e lanchonetes? Um estudo no município de São Paulo. Demetra. 2015;10(1):109-118.

[9] Kelly YB, Floof VM, Bicego C, Yeatman NH. Derailing healthy choices: an audit of vending machines at train stations in NSW. Health Promotion Journal of Australia. 2012;23(1):73-75.

[10] Glanz K, Basil M, Maibach E, Goldberg J, Snyder D. Why Americans eat what they do: taste, nutrition, cost, convenience, and weight control concerns as influences on food consumption. Journal of the American Dietetic Association. 1998;98(10):1118 1126.

[11] Burlandy L, Magalhães R, Frozi DS. Políticas Públicas de Segurança Alimentar e Nutricional. In: Rocha C, Burlandy L, Magalhães R. Segurança alimentar e nutricional: perspectivas, aprendizados e desafios para as políticas públicas. Rio de Janeiro: Editora Fiocruz; 2013.

[12] Brasil. Conselho Nacional de Segurança Alimentar e Nutricional - CONSEA. Alimentação Adequada e Saudável: direito de todos. Relatório final da 4a Conferência Nacional de Segurança Alimentar e Nutricional. Salvador: CONSEA; 2011.

[13] Brasil. Lei no 11.346, de 15 de setembro de 2006. Cria o Sistema Nacional de Segurança Alimentar e Nutricional - SISAN com vistas a assegurar o direito humano à alimentação adequada, institui a Política Nacional de Segurança Alimentar e Nutricional PNSAN, estabelece os parâmetros para a elaboração do Plano
Nacional de Segurança Alimentar e Nutricional, e dá outras providências. Brasilia: Diário Oficial da União. 18 set 2006.

[14] Maluf RS, Reis MC dos. Conceitos e Princípios de Segurança Alimentar e Nutricional. In: Rocha C; Burlandy L; Magalhães R. Segurança Alimentar e Nutricional: perspectivas, aprendizados e desafios para as políticas públicas. Rio de Janeiro: Editora Fiocruz; 2013.

[15] Companhia do Metropolitano de São Paulo [internet]. Regulamento de procedimentos relativos à obtenção de receitas não tarifárias da Companhia do Metropolitano de São Paulo Regulamento Geral. São Paulo, 2016. [acesso em 20 dez 2017]. Disponível em: http://www.metro.sp.gov.br

[16] Revista Ferroviária [internet]. Receitas não-tarifárias completam orçamento do Metrô de SP, 2014. [acesso em 20 dez 2017]. Disponível em: http://www.revistaferroviaria.com.br

[17] Companhia do Metropolitano de São Paulo [internet]. Demonstração de resultados do exercício - DRE 2017. 2017. [acesso em 14 abr 2018]. Disponível em: https://transparencia.metrosp.com.br/sites/default/files/Demons tra $\%$ C3\%A7\%C3\%A3o $\% 20$ de $\% 20$ Resultados $\% 20 \% 202017$.pdf

[18] Pimentel A. O método da análise documental: seu uso numa pesquisa historiográfica. Cad. Pesqui. 2001;114:179-195.

[19]Minayo MCS, Deslandes SF, Neto OC, Gomes R. Pesquisa Social - Teoria, método e criatividade. 21. ed. Petrópolis: Editora Vozes; 2002.

[20]Lüdke M, André MEDA. Pesquisa em educação: abordagens qualitativas. São Paulo: EPU; 1986.

[21] Oliveira MM. Como fazer pesquisa qualitativa. Petrópolis: Vozes; 2007.

[22] Cellard AA. Análise documental. In: Poupart J et al. A pesquisa qualitativa: enfoques epistemológicos e metodológicos. Petrópolis: Vozes; 2008. p.303.

[23] Sá-Silva JR, Almeida CD, Guindani JF. Pesquisa documental: pistas teóricas e metodológicas. Rev. Bras. História \& Ciências Sociais. 2009;1:1-15.

[24] Prefeitura Municipal de São Paulo. Decreto no 57.486, de 01 de dezembro de 2016. Introduz alterações no Decreto no 50.079, de 7 de outubro de 2008, que regulamenta disposições da Lei no 13.725 , de 9 de janeiro de 2004, dispõe sobre o Sistema Municipal de Vigilância em Saúde, disciplina o Cadastro Municipal de Vigilância em Saúde e estabelece os procedimentos administrativos de vigilância em saúde. São Paulo: PMSP. 01 dez 2016.

[25] Prefeitura Municipal de São Paulo. Lei Municipal no 13.725, de 9 de janeiro de 2004. Institui o Código Sanitário do Município de São Paulo. São Paulo:PMSP. 09 jan 2004. 
[26] Prefeitura Municipal de São Paulo. Secretaria Municipal da Saúde de São Paulo. Portaria no 2215/2016 - SMSG. Estabelece os procedimentos necessários para o requerimento de inscrição no Cadastro Municipal de Vigilância em Saúde - CMVS ou da Licença de Funcionamento Sanitária. São Paulo: PMSP: 2016.

[27] Brasil. Ministério da Saúde. Secretaria de Atenção à Saúde. Departamento de Atenção Básica. Política Nacional de Alimentação e Nutrição/Ministério da Saúde. Brasilia: Ministério da Saúde; 2012.

[28] Brasil. Ministério do Desenvolvimento Agrário. Programa de Aquisição de Alimentos. Brasília: Ministério do Desenvolvimento Agrário; 2012.

[29] Câmara Intersetorial de Segurança Alimentar e Nutricional. Plano Nacional de Segurança Alimentar e Nutricional: 2016/2019. Brasília: CAISAN; 2016.

[30] Brasil. Decreto o 7.794, de 20 de agosto de 2012. Institui a Política Nacional de Agroecologia e Produção Orgânica. Brasília: Diário Oficial da Uniao. 22 ago 2012.

[31] Brasil. Decreto no 8.553, de 3 de novembro de 2015. Institui o Pacto Nacional para Alimentação Saudável. Brasilia: Diário Oficial da União. 04 nov 2015.

[32] Organização das Nações Unidas. Transformando Nosso Mundo: A Agenda 2030 para o Desenvolvimento Sustentável. Nova York: ONU; 2015.

[33] Organização Pan-Americana da Saúde [internet]. Década de Ação das Nações Unidas sobre Nutrição (2016-2025). [acesso em 20 abr 2018]. Disponível em: http://www.paho.org/bra/index.php?option=com_content\&view $=$ article\&id $=5434$ :decada-de-acao-dasnacoes-unidas-sobrenutricao-2016-2025 \&Itemid $=992$

[34] Prefeitura Municipal de São Paulo. 1o Plano Municipal de Segurança Alimentar e Nutricional 2016/2020 - PLAMSAN. São Paulo: PMSP; 2016.

[35] Milan Urban Food Policy Pact [internet]. Text. [acesso em 15 abr 2018]. Disponível em: http://www.milanurbanfoodpolicypact.org/text

[36] São Paulo. Secretaria de Agricultura e Abastecimento [internet]. Produtos orgânicos são comercializados no metrô de SP, 2002. [acesso em 29 mar 2018]. Disponível em: http://www.agricultura.sp.gov.br/noticias/produtos-organicossao-comercializados-no-metro-de-sp

[37] São Paulo. Secretaria de Agricultura e Abastecimento [internet]. Comércio: Projeto "Estação Economia" vende frutas de Natal a preços populares, 2000. [acesso em 29 mar 2018]. Disponível em: http://www.saopaulo.sp.gov.br/spnoticias/ultimas-noticias/ comercio-projeto-estacao-economia-vende-frutas-de-natal-aprecos-populares
[38] São Paulo. Secretaria de Agricultura e Abastecimento [internet]. Estação economia vende panetones a preços até $60 \%$ mais baixo que supermercados, 2002. [acesso em 29 mar 2018]. Disponível em: http://www.agricultura.sp.gov.br/noticias/estacao-economiavende-panetones-a-precos-ate-60-mais-baixo-que-supermercados

[39] Mercado Físico Rural [internet]. Governo de SP estuda seguro contra cancro e greening, 2006. [acesso em 08 ago 2018]. Disponível em: http://noticias.mfrural.com.br/noticiaagricola/governo-de-sp-estuda-seguro-contra-cancro-e-greening8370.aspx.

[40] Nabuco MR.; Porto SI. Como planejar e executar o abastecimento alimentar municipal. In: Belick W; Maluf RS. Abastecimento e segurança alimentar: os limites da liberalização. Campinas: IE/UNICAMP; 2000. p. 209-234. 